\title{
Drug-induced parkinsonism: what should a psychiatrist know?
}

\author{
Santiago Vásquez-Builes ${ }^{1,2^{*}}$, Catalina Salazar-Duque ${ }^{1}$, María P. Tieck-Fernández ${ }^{1}$, Isabel C. Rojas-Gallego ${ }^{1}$, \\ and Gustavo A. Díaz-Silva ${ }^{1,2}$ \\ ${ }^{1}$ Semillero de neurociencias, Universidad CES, Medellín, Colombia; ${ }^{2}$ Clinical Neurology, Instituto Neurológico de Colombia, Medellín, Colombia
}

\begin{abstract}
Drug-induced parkinsonism is the main cause of secondary parkinsonism in the world. Antipsychotics, antidepressants, and mood stabilizers are the most common drugs implicated in the parkinsonism. This is why psychiatrists and neurologists must have deep knowledge of the diverse aspects of these disorders, to take the best diagnostic and therapeutic approaches.
\end{abstract}

Key words: Parkinsonism. Drug-induced parkinsonism. Psychiatrist.

\section{Parkinsonismo inducido por medicamentos: ¿Qué debería conocer el psiquiatra?}

\section{Resumen}

El parkinsonismo inducido por medicamentos es la principal causa de parkinsonismo secundario en el mundo. Los antipsicóticos, antidepresivos y moduladores del estado de ánimo son los medicamentos más frecuentemente implicados en el desarrollo de este trastorno. Por tanto, es necesario que psiquiatras y neurólogos conozcan profundamente las diversas características del parkinsonismo inducido por medicamentos, para tomar las mejores decisiones diagnósticas y terapéuticas en estos pacientes.

Palabras clave: Parkinsonismo. Parkinsonismo inducido por medicamentos. Psiquiatría.

\section{Introduction}

Drug-induced parkinsonism (DIP) is a clinical syndrome characterized by bradykinesia, tremor, stiffness, and postural instability. Idiopathic Parkinson's disease (PD) and DIP represent the two main causes of parkinsonism in the world ${ }^{1}$. In the 50 s, the first DIP descriptions were made, and they linked the syndrome to the use of chlorpromazine and reserpine, drugs that were used at the time as antipsychotic and antihypertensive, respectively ${ }^{2}$. In later years, parkinsonism was recognized as a frequent adverse effect related to different antipsychotic drugs and later to other numerous drugs of other pharmacologic groups (Table 1).

\section{Objective}

The purpose of this article is to contribute to a bigger understanding and recognition of DIP through an updated description about clinical and therapeutic aspects, etiology, and physiopathology, diving into key concepts and situations for the psychiatrist.

\section{Correspondence:}

*Santiago Vásquez-Builes

E-mail: santiagovasquezb @ hotmail.com
Available online: 07-07-2021

Rev Mex Neuroci. 2021;22(4):146-151 www.revmexneurociencia.com 1665-5044/ @ 2020 Academia Mexicana de Neurología A.C. Published by Permanyer. This is an open access article under the CC BY-NC-ND license (http://creativecommons.org/licenses/by-nc-nd/4.0/). 
Table 1. Drugs associated with DIP

\begin{tabular}{|c|c|}
\hline Mechanism & Pharmacological group/drug \\
\hline $\begin{array}{l}\text { D2 receptors blockers } \\
\text { (typical and atypical) }\end{array}$ & $\begin{array}{l}\text { Typical antipsychotics: haloperidol, } \\
\text { levomepromazine, etc. } \\
\text { Atypical antipsychotics: risperidone, } \\
\text { olanzapine, ziprasidone, aripiprazole, } \\
\text { quetiapine }\end{array}$ \\
\hline Depletion of dopamine & Tetrabenazine \\
\hline $\begin{array}{l}\text { Dopamine synthesis } \\
\text { blockers }\end{array}$ & Alpha methyldopa \\
\hline $\begin{array}{l}\text { Calcium channels } \\
\text { blockers }\end{array}$ & Flunarizine, cinnarizine \\
\hline Antiemetics & Metoclopramide \\
\hline $\begin{array}{l}\text { Calcium channels } \\
\text { blockers }\end{array}$ & Diltiazem, verapamil \\
\hline Antiepileptics & Valproic acid, phenytoin, levetiracetam \\
\hline Mood stabilizers & Valproic acid, lithium \\
\hline Antiarrhythmics & Amiodarone, procaine \\
\hline Immunosuppressors & Cyclosporine, tacrolimus \\
\hline Antidepressants & Fluoxetine, sertraline \\
\hline Antivirals & Acyclovir, vidarabine, antiretrovirals \\
\hline
\end{tabular}

\section{Methodology}

A literature research in the PubMed database was made, using a combination of the following key words: "DIP," "parkinsonism AND neuroleptics," "parkinsonism AND antidepressants," "parkinsonism AND mood stabilizers," "parkinsonism and psychiatry," and "parkinsonism and drugs." Additional articles used as references from the obtained articles of the mentioned research were also included. We selected publications in English and Spanish. We reviewed the articles and chose the ones that enabled to reach the aim of the present study.

\section{Epidemiology}

Savica et al. found $11,9 \%$ of parkinsonism in the OImstead county, Minnesota, between 1976 and 2005, corresponded to DIP and the estimated incidence rate was $3,3 / 100,000$ persons-year ${ }^{1}$. Furthermore, they identify a tendency toward a decrease in the rate of DIP incidence of the $68,6 \%$ from 1976 to $2005^{1}$. In Korean population, the reported incidence has been greater than the one described in American population and in contrast to America, the Korean records showed an increase of DIP incidence from 7,1 to $13,9 / 100,000$ persons-year in 2012 and 2015, respectively $(p<0,0001)^{3}$. Among Latin-American population, some studies evaluated the epidemiology behavior of DIP. The Pietà study made in Brazil found that DIP represents the $12,3 \%$ of parkinsonism cases with a raw prevalence of 1300 cases $/ 100,000$ people ${ }^{4}$. This estimate was lower compared to the one reported in the previous studies in Brazilian population as well ${ }^{5}$. In specific scenarios, such as neurology and movement disorders consult, studies report that between $6,8 \%$ and $56 \%$ of evaluated patients for parkinsonism correspond to DIP ${ }^{6,7}$. Despite the described studies, the incidence and prevalence of DIP remains unknown due to a lack of record of this syndrome and the frequent confusion between DIP and idiopathic $\mathrm{PD}^{7,8}$.

\section{Risk factors}

The OMS pharmacovigilance database analysis (Vigibase $^{\circledR}$ ) showed that people over 75 years old are at the highest risk of developing this disorder (reporting odds ratio $[R O R]=2,12$; IC 95\% 1,98-2,26) $)^{9}$. Some factors may explain the risk in this population, such as higher exposure to drugs for behavior disorders, higher polypharmacy, higher risk for cognitive impairment, and less nigrostriatal integrity ${ }^{10,11}$.

Many studies have reported a higher DIP frequency among women ${ }^{11}$. However, Germany et al. found the risk for DIP was higher in men compared to women (ROR $=1,39$, IC 95\%: 1,31-1,47) ${ }^{9}$, when they adjusted the total ratio of pharmacological adverse effects reports. Furthermore, genetic factors have been associated with higher predisposition to parkinsonism development, therefore not everyone exposed to antipsychotics develop this disorder ${ }^{10,12}$.

\section{Key elements for definition}

DIP is defined as a parkinsonian syndrome secondary to the use of drugs, which alters the dopaminergic function in persons without previous parkinsonism history ${ }^{1}$. A key aspect when drugs are linked with parkinsonism development is the existence of a temporal relationship between the use of a drug to the emergence of symptoms ${ }^{13}$. However, the gap between the initiation of a drug and the parkinsonism manifestation is variable, going from a few days to month ${ }^{14,15}$. The French pharmacovigilance database analysis enabled to identify two peaks in the emergence of symptoms. The initial peak occurred in the first 3 months of drug 
use and it was mainly associated to D2 receptor blockers and antidepressants. The second peak occurred between 9 and 12 months and it was especially associated to calcium channel blockers ${ }^{14,15}$. On the other hand, it is considered that the parkinsonian syndrome resolution must come in the first 6 months after the drug suspension, although this time is also variable and controversial ${ }^{15-17}$.

\section{Physiopathology}

Movement control involves many cortical and subcortical regions. The planning and movement performance starts in the premotor and motor areas of the cerebral cortex; while the basal nuclei, the substantia nigra, the subthalamic nucleus, and the red nucleus among others also play a fundamental role in the reception, integration, and regulation of the information coming from the cerebral cortex, cerebellum, and other nervous system regions ${ }^{18}$. A great number of neurotransmitters interact in these cerebral regions, including monoamines, acetylcholine, glutamate, and gamma-aminobutyric acid (GABA) ${ }^{18}$.

The main central dopaminergic pathways are the nigrostriatal, mesolimbic, and mesocortical, which emerge from the substantia nigra, the ventral tegmental area, and the retrorubral region ${ }^{19}$. The substantia nigra regulates the basal ganglia and its effect is mediated by dopamine. Until now, five types of dopamine receptors have been described, from D1 to D5, grouped in two families, D1-like and D2-like ${ }^{20}$. The D1-like family includes D1 and D5 and they are characterized by Gs protein coupled receptors, they stimulate adenylyl and increase the intracellular cAMP levels, in general, they lead to an excitatory effect. The D2-like family includes D2-D4 receptors, they are Gi protein coupled receptors and their stimulation induces opposite effects to the ones described for the D1-like receptors family ${ }^{18,20}$.

The antipsychotics block the D2 receptors in the mesolimbic and mesocortical pathways. In the corpus striatum, the D2 receptor stimulation, the inhibitory kind, regulates the GABA release in the striatal neurons, avoiding the excess of an inhibitory tone in the indirect pathway and maintaining a balance with the direct pathway ${ }^{21}$. Drugs that alter the nigrostriatal pathway may modify the dopamine mediated negative feedback toward the corpus striatum, which induce a deeper activation and an increase of the inhibitory tone coming from the striatum ${ }^{19}$. It has been estimated that the emergence of parkinsonian symptoms comes when more than $80 \%$ of the D2 receptors are blocked ${ }^{22}$.
However, not only the percentage of occupied receptors is important but also the drug-receptor union. Drugs like aripiprazole may reach more than $90 \%$ of blockage without producing parkinsonian symptoms, it seems to be explained by a high drug-receptor clearance rate ${ }^{23}$.

The hyperkinetic symptoms observed in DIP, such as oromandibular dyskinesia, may be also explained by the prolonged blockage of dopaminergic receptors; but in this case, the dyskinesia is due to the compensatory hypersensitivity they develop ${ }^{24}$. Other implicated mechanisms include type 2 vesicular monoamine transporter 2 blockage and the modification of calcium channels at the presynaptic terminal ${ }^{25}$.

\section{Drugs associated with parkinsonism}

Numerous drugs from different pharmacological groups frequently used in the neurology and psychiatric practice have been associated to parkinsonism emergence.

\section{Antipsychotics}

Up to $60 \%$ of DIP cases have been attributed to the psychopharmaceutic drugs, especially antipsychotics ${ }^{26}$. In general, a higher risk is attributed to typical antipsychotics because these drugs have a greater affinity and minor speed of clearance over the D2 receptors, while the atypical antipsychotics may have a more restricted effect over the $2 \mathrm{~A}$ serotonin receptors ${ }^{27}$. However, the risk of parkinsonism with atypical antipsychotics is variable and, in general, when high dosage is used, their risk is comparable to the risk of typical antipsychotics $^{28}$. Gomez et al. evaluated this risk among patients with schizophrenia, who frequently get high dosage of this drugs and they found that the DIP prevalence was similar among patients, who got both types of antipsychotics ${ }^{29}$.

Risperidone, an atypical antipsychotic, has a dosage-dependent action on D2 receptors, therefore, their effect at a high dosage emulates a typical antipsychotic $a^{a c t i o n}{ }^{27}$. Olanzapine is another atypical antipsychotic that has shown a high potential to induce parkinsonism and other extrapyramidal effects ${ }^{27}$. On the other hand, aripiprazole is an atypical antipsychotic, with a novel mechanism of action and a fast speed of clearance from the receptor. Initially, there was considering that aripiprazole had a low risk of inducing parkinsonism, although this has been controversial in recent publications ${ }^{23}$. The two antipsychotics with the lowest risk for parkinsonism are clozapine and quetiapine ${ }^{27,30}$. 


\section{Antidepressants}

Although rare, the association between antidepressants and parkinsonism has also been reported. A retrospective study of pharmacovigilance reported that $8 \%$ of DIP cases have been associated with the use of antidepressants ${ }^{15}$. Among these drugs, serotonin reuptake inhibitors and dual-action antidepressants stand out, especially sertraline and escitalopram $^{15}$. Hawthorne et al. found that parkinsonism was the most frequent extrapyramidal reaction associated with antidepressants and $80,2 \%$ of all the extrapyramidal effects were associated with serotonin reuptake inhibitors ${ }^{31}$. It is believed that the mechanism by which the antidepressants may induce parkinsonism is because of the increase of the serotoninergic activity at the raphe nucleus, which generates an inhibitory action over the striatal and tegmental dopaminergic pathways ${ }^{31}$.

\section{Mood stabilizers}

Mood stabilizers may also induce extrapyramidal effects ${ }^{32}$. Among this group, the valproic acid is the drug which associates the most with tremor and parkinsonism $^{32-34}$. This drug has several mechanisms of action, the blockage of voltage-dependent sodium channels and the inhibition of GABA-metabolizing enzymes generate an increase of GABA in the striatum nuclei, this mechanism may explain its parkinsonian effects ${ }^{33,34}$. Strikingly, it has been described that there is no direct relationship between serum valproic acid levels and the development of parkinsonism; furthermore, the emergence of symptoms may appear even years after the start of the drug ${ }^{33,34}$. Zadikoff et al. reported parkinsonism in $10 \%$ of patients taking valproic acid $^{32}$.

\section{Persistent DIP: DIP or idiopathic PD?}

Up to $30 \%$ of the patients with DIP may present a persistent or progressive parkinsonian syndrome ${ }^{35}$. The persistence or the deterioration of parkinsonian syndrome, as well as a complete remission with posterior symptom recurrence after the suspension of the drug, may indicate the existence of a preclinical idiopathic PD state, which was uncovered by the drugs ${ }^{35}$. In fact, it has been reported that just $43 \%$ of patients with DIP presented normal activity in the nigrostriatal system, which may indicate that a great amount of DIP patients really corresponded to PD uncovered by drugs more than a pure DIP ${ }^{36,37}$.
Although clinical manifestations alone are not sufficient to differentiate PD and DIP, some authors have reported semiologic differences that may orient the differentiation ${ }^{35}$. The presentation of idiopathic PD is slow and progressive, while DIP has usually a subacute start and the evolutions tend to be stationary ${ }^{38}$. In addition, Yomtoob et al. reported that patients with more than main two manifestations of parkinsonism have a greater probability of having PD than DIP26. Several studies have described a greater asymmetric parkinsonian prevalence among PD uncovered by drugs than a pure DIP ${ }^{36,39}$. Pieters et al. found $20,8 \%$ of DIP patients presents with asymmetric parkinsonian symptoms and the asymmetric presentation was associated with a greater severity of symptoms, especially cognitive behavioral symptoms and psychopathology ${ }^{40}$. However, even one-third of pure DIP patients may also exhibit asymmetric parkinsonian symptoms ${ }^{39}$. Other more frequent characteristics of DIP are hypomimia, akinetic-rigid phenotype, upper extremities impairment, and higher frequency of postural tremor ${ }^{41}$.

Non-motor symptoms may also be crucial for the differentiation of these two types of parkinsonism. Morley et al. found that non-motor symptoms such as constipation $(p=0,02)$ and erectile dysfunction $(p=0,05)$ were significantly more frequent in PD than in DIP. On the other hand, cognitive complains and psychopathology were higher in DIP. Although hyposmia was frequent in DIP and PD (88\% vs. $57 \%$ ), it was significantly more frequent in DIP $(p=0,003)^{41}$. The evaluation of the olfactory function is a tool with a good performance for this differentiation and the result of the olfactory test may predict with great accuracy if patients with parkinsonism could recover after the suspension of the involved drug ${ }^{41,42}$. Kim et al. evaluated other symptoms using the non-motor symptoms scale in patients with PD, DIP, and healthy controls, they found that symptoms such as urinary and sleep impairment, attention deficit, and hyposmia were associated with PD, even after adjusting confounding variables ${ }^{43}$.

\section{Treatment}

The management of DIP includes prevention, early recognition, and modification of the pharmacological therapy that is potentially causing parkinsonism 7 . Because DIP is an iatrogenic manifestation, doctors must be aware of the safety profile of the drugs they prescribe and the characteristics of the patients, especially older patients. Patients with high risk for developing 
DIP receiving drugs that alter dopaminergic function must be evaluated regularly with the intention to detect early parkinsonian symptoms ${ }^{44}$.

The main DIP treatment is the suspension of the involved drug. In some cases, there is no need to change the drug for another. For example, some patients with migraine treated with valproic acid or flunarizine, who have achieved good symptoms control, do not need to continue the drug nor change it. However, in other cases, a change of the drug is needed, such as patients receiving typical antipsychotics, who may benefit from a change to an atypical antipsychotic. Patients using an atypical antipsychotic such as risperidone may improve with a change to another atypical antipsychotics with lower parkinsonism risk such as clozapine or quetiapine. Patients cannot change the implicated drug because of their illness, the drug must be reduced to the minimum possible dosage ${ }^{44}$.

Amantadine and anticholinergics, including biperiden, benztropine, or trihexyphenidyl, have been used for the control of symptoms but they lack strong evidence to support their use $\mathrm{e}^{25,44}$.

\section{Prognosis}

The majority of DIP cases are reversible with the suspension of the drug, that is, why DIP prognosis is usually benign. However, up to $30 \%$ of patients with DIP may develop a persistent or progressive parkinsonian syndrome and there is the hypothesis that many of these patients have another cause of parkinsonism. Yoo et al. reported that patients, who reach a full recovery, showed greater functional connectivity in prefrontal and cerebellar regions ${ }^{45}$. On the other hand, there is a possibility that DIP behaves as a risk factor for PD. For example, a cohort study showed that the long-term risk for PD increased 2,3 times after the exposure to neuroleptics ${ }^{46}$.

It seems that the complete remission of parkinsonian symptoms after the suspension of the drug is not an accurate indicator of DIP diagnosis. A study of autopsies found pathological findings matching PD in two patients who have had DIP diagnosis and have reached a complete remission of symptoms after the drug suspension ${ }^{47}$.

Functional imaging has shown a good performance predicting the evolution of parkinsonism with great diagnostic utility. However, patients with DIP and normal activity of the dopamine transporter may also present persistence of parkinsonism ${ }^{48}$.

\section{Conclusion}

DIP is one of the main causes of parkinsonism in the world and this syndrome will continue to be an important cause of morbidity, especially in older population. In most cases, DIP is a pure syndrome without dysfunction of the nigrostriatal system. However, a variable but significant percentage of patients presents previous disturbances in the nigrostriatal system, which allows to think that in these cases the drug uncovers a previous neurodegenerative disease. In both cases, parkinsonism has an important morbidity for patients, therefore, it is important to prevent it and to recognize it in early stages to limit its clinical impact.

\section{Funding}

None.

\section{Conflicts of interest}

None.

\section{Ethical disclosures}

Protection of human and animal subjects. The authors declare that no experiments were performed on humans or animals for this study.

Confidentiality of data. The authors declare that no patient data appear in this article.

Right to privacy and informed consent. The authors declare that no patient data appear in this article.

\section{References}

1. Savica R, Grossardt BR, Bower JH, Ahlskog JE, Mielke MM, Rocca WA. Incidence and time trends of drug-induced parkinsonism: a 30-year population-based study. Mov Disord. 2017;32:227-34.

2. Hall RA, Jackson RB, Swain JM. Neurotoxic reactions resulting from chlorpromazine administration. J Am Med Assoc. 1956;161:214-8.

3. Han S, Kim S, Kim H, Shin HW, Na KS, Suh HS. Prevalence and incidence of Parkinson's disease and drug-induced parkinsonism in Korea. BMC Public Health. 2019;19:1328.

4. Vale TC, Barbosa MT, Resende EP, Maia DP, Cunningham MC, Guimarães HC, et al. Parkinsonism in a population-based study of individuals aged $75^{+}$years: the Pietà study. Parkinsonism Relat Disord. 2018;56:76-81.

5. Barbosa MT, Caramelli P, Maia DP. Parkinsonism and Parkinson's disease in the elderly: a community-based survey in Brazil (the Bambuí study). Mov Disord. 2006;21:800-8.

6. Marti-Masso JF, Poza JJ. Cinnarizine-induced parkinsonism: ten years later. Mov Disord. 1998;13:453-6.

7. Esper CD, Factor SA. Failure of recognition of drug-induced parkinsonism in the elderly. Mov Disord. 2008;23:401-4.

8. Benito-León J, Bermejo-Pareja F, Rodríguez J, Molina JA, Gabriel R, Morales JM, Neurological Disorders in Central Spain (NEDICES) Study Group. Prevalence of PD and other types of parkinsonism in three elderly populations of central Spain. Mov Disord. 2003;18:267-74.

9. de Germay S, Montastruc F, Carvajal A, Lapeyre-Mestre M, Montastruc JL. Drug-induced parkinsonism: revisiting the epidemiology using the WHO pharmacovigilance database. Parkinsonism Relat Disord. 2020;70:55-9. 
10. Greenbaum L, Lerer B. Pharmacogenetics of antipsychotic-induced movement disorders as a resource for better understanding Parkinson's disease modifier genes. Front Neurol. 2015;6:27.

11. Sheehan R, Horsfall $L$, Strydom A, Osborn D, Walters $K$, Hassiotis A. Movement side effects of antipsychotic drugs in adults with and without intellectual disability: UK population-based cohort study. BMJ Open 2017;7:e017406.

12. Bakker PR, Bakker E, Amin N, van Duijn CM, van Os J, van Harten PN Candidate gene-based association study of antipsychotic-induced movement disorders in long-stay psychiatric patients: a prospective study. PLoS One. 2012;7:e36561.

13. Bower JH, Maraganore DM, McDonnell SK, Rocca WA. Incidence and distribution of parkinsonism in Olmsted county, Minnesota, 1976-1990. Neurology. 1999:52:1214-20.

14. Llau ME, Nguyen L, Senard JM, Rascol O, Montastruc JL. Drug-induced parkinsonian syndromes: a 10-year experience at a regional center of pharmaco-vigilance. Rev Neurol (Paris). 1994;150:757-62.

15. Bondon-Guitton E, Perez-Lloret S, Bagheri H, Brefel C, Rascol O, Montastruc JL. Drug-induced parkinsonism: a review of 17 years' experience in a regional pharmacovigilance center in France. Mov Disord. 2011;26:2226-31.

16. Lim TT, Ahmed A, Itin I. Is 6 months of neuroleptic withdrawal sufficient to distinguish drug-induced parkinsonism from Parkinson's disease? Int J Neurosci. 2013;123:170-4.

17. Randhawa J, Mehanna R. Drug induced parkinsonism: symptomatic beyond 22 months. Parkinsonism Relat Disord. 2019;66:267-8.

18. Lanciego JL, Luquin N, Obeso JA. Functional neuroanatomy of the basa ganglia. Cold Spring Harb Perspect Med. 2012;2:a009621.

19. Morgan JC, Kurek JA, Davis JL, Sethi KD. Insights into pathophysiology from medication-induced tremor. Tremor Other Hyperkinet Mov (N Y). 2017;7:442.

20. Mishra A, Singh S, Shukla S. Physiological and functional basis of dopamine receptors and their role in neurogenesis: possible implication for Parkinson's disease. J Exp Neurosci. 2018;12:79829.

21. Burke DA, Rotstein HG, Alvarez VA. Striatal local circuitry: a new framework for lateral inhibition. Neuron. 2017;96:267-84.

22. Farde L, Nordström AL, Wiesel FA, Pauli S, Halldin C, Sedvall G. Positron emission tomographic analysis of central D1 and D2 dopamine receptor occupancy in patients treated with classical neuroleptics and clozapine. Relation to extrapyramidal side effects. Arch Gen Psychiatry. 1992;49:538-44.

23. Selfani K, Soland VL, Chouinard S, Huot P. Movement disorders induced by the atypical antipsychotic aripiprazole. Neurologist. 2017:22:24-8.

24. Kapur S, Zipursky R, Jones C, Remington G, Houle S. Relationship between dopamine D2 occupancy, clinical response, and side effects: a double-blind PET study of first-episode schizophrenia. Am J Psychiatry. 2000;157:514-20.

25. Galoppin M, Berroir P, Soucy JP, Suzuki Y, Lavigne GJ, Gagnon JF, et al. Chronic neuroleptic-induced parkinsonism examined with positron emission tomography. Mov Disord. 2020;35:1189-98.

26. Yomtoob J, Koloms K, Bega D. DAT-SPECT imaging in cases of drug-induced parkinsonism in a specialty movement disorders practice. Parkinsonism Relat Disord. 2018;53:37-41.

27. Druschky K, Bleich S, Grohmann R, Engel RR, Toto S, Neyazi A, et al Severe parkinsonism under treatment with antipsychotic drugs. Eur Arch Psychiatry Clin Neurosci. 2020;270:35-47.

28. Schotte A, Janssen PF, Gommeren W, Van Gompel P, Lesage AS, De Loore K, et al. Risperidone compared with new and reference antipsychotic drugs: in vitro and in vivo receptor binding. Psychopharmacology (Berl). 1996;124:57-73.
29. Gómez JC, Sacristán JA, Hernández J, Breier A, Carrasco PR, Saiz CA et al. The safety of olanzapine compared with other antipsychotic drugs: results of an observational prospective study in patients with schizophrenia (EFESO Study). Pharmacoepidemiologic study of olanzapine in schizophrenia. J Clin Psychiatry. 2000;61:335-43.

30. Rabey JM, Prokhorov T, Miniovitz A, Dobronevsky E, Klein C. Effect of quetiapine in psychotic Parkinson's disease patients: a double-blind labeled study of 3 months' duration. Mov Disord. 2007;22:313-8.

31. Hawthorne JM, Caley CF. Extrapyramidal reactions associated with serotonergic antidepressants. Ann Pharmacother. 2015;49:1136-52.

32. Zadikoff C, Munhoz RP, Asante AN, Politzer N, Wennberg R, Carlen P, et al. Movement disorders in patients taking anticonvulsants. J Neurol Neurosurg Psychiatry. 2007;78:147-51.

33. Baizabal-Carvallo JF, Alonso-Juarez M. Valproate-induced rest tremor and parkinsonism. Acta Neurol Belg. 2019;4-5

34. Alonso-Juarez M, Torres-Russotto D, Crespo-Morfin P, Baizabal-Carvallo JF. The clinical features and functional impact of valproate-induced tremor. Parkinsonism Relat Disord. 2017:44:147-50.

35. Brigo F, Erro R, Marangi A, Bhatia K, Tinazzi M. Differentiating drug-induced parkinsonism from Parkinson's disease: an update on non-motor symptoms and investigations. Parkinsonism Relat Disord. 2014;20:808-14.

36. Diaz-Corrales FJ, Sanz-Viedma S, Garcia-Solis D, Escobar-Delgado T, Mir P. Clinical features and 123I-FP-CIT SPECT imaging in drug-induced parkinsonism and Parkinson's disease. Eur J Nucl Med Mol Imaging. 2010;37:556-64.

37. Tinazzi M, Cipriani A, Matinella A, Cannas A, Solla P, Nicoletti A, et al ${ }^{123}$ IFP-CIT single photon emission computed tomography findings in drug-induced Parkinsonism. Schizophr Res. 2012;139:40-5.

38. Munhoz RP, Filho DB, Teive HA. Not all drug-induced parkinsonism are the same: the effect of drug class on motor phenotype. Neurol Sci. 2017;38:319-24.

39. Shin HW, Kim JS, Oh M, You S, Kim YJ, Kim J, et al. Clinical features of drug-induced parkinsonism based on 18F FP-CIT positron emission tomography. Neurol Sci. 2015;36:269-74.

40. Pieters LE, Bakker PR, van Harten PN. A symmetric drug-induced parkinsonism and psychopathology: a prospective naturalistic study in longstay psychiatric patients. Front Psychiatry. 2018;9:18.

41. Morley JF, Pawlowski SM, Kesari A, Maina I, Pantelyat A, Duda JE. Motor and non-motor features of Parkinson's disease that predict persistent drug-induced Parkinsonism. Parkinsonism Relat Disord. 2014;20:738-42.

42. Morley JF, Cheng G, Dubroff JG, Wood S, Wilkinson JR, Duda JE. OIfactory impairment predicts underlying dopaminergic deficit in presumed drug-induced parkinsonism. Mov Disord Clin Pract. 2016;4:603-6.

43. Kim JS, Youn J, Shin H, Cho JW. Nonmotor symptoms in drug-induced parkinsonism and drug-naïve Parkinson disease. Can J Neurol Sci. 2013;40:36-41.

44. David MC, Sweet AR, Keshavan SM. Managing antipsychotic-induced parkinsonism. Drug Saf. 1999;20:269-75.

45. Yoo HS, Bak Y, Chung SJ, Lee $Y$, Ye SB, Sohn YH, et al. Impaired functional connectivity of sensorimotor network predicts recovery in drug-induced parkinsonism. Parkinsonism Relat Disord. 2020;74:16-21.

46. Foubert-Samier A, Helmer C, Perez F, Le Goff M, Auriacombe S, Elbaz $A$, et al. Past exposure to neuroleptic drugs and risk of Parkinson disease in an elderly cohort. Neurology. 2012;79:1615-21.

47. Shuaib UA, Rajput AH, Robinson CA, Rajput A. Neuroleptic-induced Parkinsonism: clinicopathological study. Mov Disord. 2016;31:360-5.

48. Hong JY, Sunwoo MK, Oh JS, Kim JS, Sohn YH, Lee PH. Persistent drug-induced parkinsonism in patients with normal dopamine transporter imaging. PLoS One. 2016;11:e0157410. 